\title{
INTEGRATING GENDER EQUITY INTO BUSINESS NETWORKS FOR NUTRITION
}

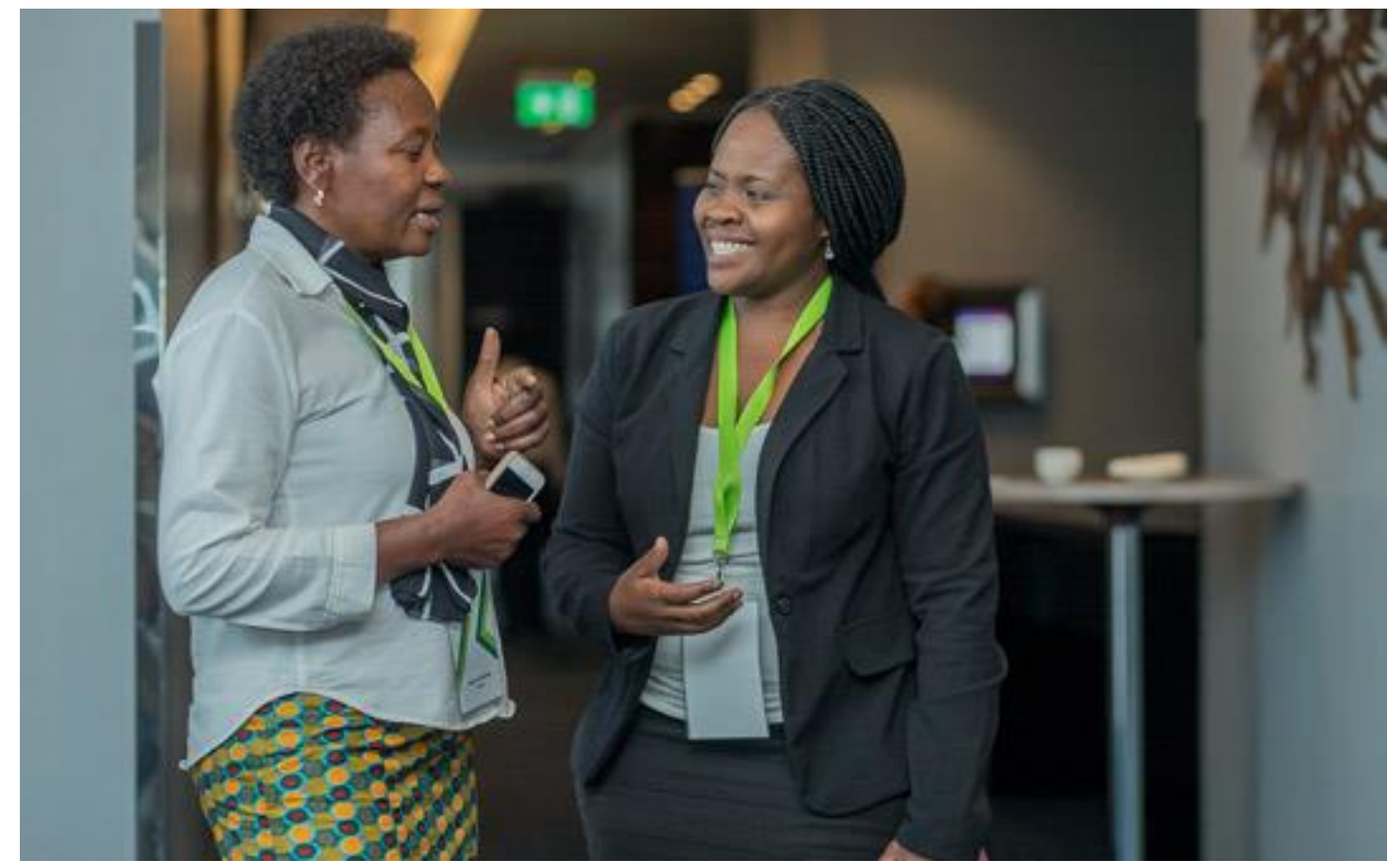

GAIN Working Paper n¹2

October, 2020

Stella Nordhagen 


\section{ABOUT GAIN}

The Global Alliance for Improved Nutrition (GAIN) is a Swiss-based foundation launched at the UN in 2002 to tackle the human suffering caused by malnutrition. Working with governments, businesses and civil society, we aim to transform food systems so that they deliver more nutritious food for all people, especially the most vulnerable.

\section{Recommended citation}

Nordhagen S. Integrating Gender Equity into Business Networks for Nutrition. Global Alliance for Improved Nutrition (GAIN). Working Paper \#12. Geneva, Switzerland, 2020. DOI:

https://doi.org/10.36072/wp.12

\section{(C) The Global Alliance for Improved Nutrition (GAIN)}

This work is available under the Creative Commons Attribution-Non-Commercial-Share Alike 4.0 IGO licence (CC BY-NC-SA 4.0 IGO; https://creativecommons.org/licenses/by-nc-sa/4.0/). Under the terms of this licence, you may copy, redistribute, and adapt the work for non-commercial purposes, provided the work is appropriately cited, as indicated below. In any use of this work, there should be no suggestion that GAIN endorses any specific organisation, products or services. The use of the GAIN logo is not permitted. If you adapt the work, then you must license your work under the same or equivalent Creative Commons license. The contributions of third parties do not necessarily represent the view or opinion of GAIN.

\section{Acknowledgements}

Thanks to Paula Ortiz for assistance with the literature review and to Laurene Aubert, Asma Badar, Uduak Igbeka, Emily Heneghan Kasoma, Noor Alam Khan, Saul Morris, Christina Nyhus-Dhillon, Hannah Rowlands, Jonathan Tench, and Lynnette Neufeld for their feedback during the process of developing this paper. All photographs included in this document have been taken with consent for use in publications.

\section{GAIN WORKING PAPER SERIES}

The GAIN Working Paper Series provides informative updates on programme approaches, research and evaluations, and on topics of relevance for our work.

The Global Alliance for Improved Nutrition (GAIN)

Rue de Varembé 7

1202 Geneva

Switzerland

T: +41227491850

E: info@gainhealth.org

www.gainhealth.org 


\section{SUMMARY}

Starting a business is challenging-particularly in the agriculture and food sector in a low- or middle-income country, and particularly for women, who face numerous barriers to starting and running a firm. Business networks can play an important role in helping women (and men) navigate these challenges by providing them with access to information, contacts, and resources. However, they can also themselves be affected by existing gender norms and biases, potentially even reinforcing them. To understand how to make the work of business networks (and particularly those that aim to improve nutrition) more gender sensitive, this paper summarises the literature on women in business networks and related gender equity issues. The review uncovers numerous advantages to networks, some potential pitfalls, and certain differences between men and women in terms of network access and use. The paper then uses the insights emerging from that review to offer recommendations for how to adapt business network-based programming to better promote gender equity.

\section{KEY MESSAGES}

- Networks (formal or informal) convey numerous benefits for businesses, including access to knowledge, opportunities, and partners; these can be particularly important for women, who may have difficulty breaking into predominantly male networks.

- However, networks can also work to reinforce gender biases and other social barriers if care is not taken to make them inclusive and open.

- While women generally use business networks in the same way men do (i.e., to develop skills, access work-related opportunities, or meet others who can help advance their careers), women tend to place a higher value on skills development, gaining support, and sharing experiences.

- Accessing networking events, and benefiting from them equally, can be more difficult for women in some contexts due to limitations on their mobility and time.

- There is debate about the value of female-only versus mixed-gender networks in supporting women; female-only networks have advantages as well as drawbacks, such as cutting women off from potentially useful contacts with men.

- There are a number of steps that those who convene and support business networks can take to help their networks become more gender equitable and empowering of women, including adjusting recruiting and meeting approaches. 


\section{BACKGROUND AND OBJECTIVE}

Starting a business is hard anywhere, but it is particularly hard in low- and middle-income countries (LMICs). With one exception, all low-income countries rank in the bottom half of countries worldwide on the World Bank's 'Ease of Doing Business' Index, based on scores assigned across ten topics such as registering property, paying taxes, and enforcing contracts (1). The same is true for the majority of lower-middle income countries. In Sub-Saharan Africa, for example, it takes an average of 21.5 days to start a business (versus 9.2 in high-income OECD countries) and 96 hours to comply with required documentation rules for importing goods (the OECD equivalent is 3 hours); the average cost of enforcing a contract is $41.6 \%$ of the claim value (twice as much as in high-income OECD countries).

These challenges are exacerbated in the agri-food sector, due to the sector's perceived high risk and low return (2). This is unfortunate, as the private sector, and particularly small- and medium-sized firms, play central roles in food supply chains throughout LMICs (3) —and therefore are essential for reducing hunger and improving nutrition. The barriers to starting and running a business in LMICs, in the agri-food sector or otherwise, also tend to be higher for women due to lower access to financial capital and technology; lower human capital; restrictions on time use and mobility; and negative social attitudes (4).

One potential resource that can help women (and men) navigate the challenges of starting and running a food business is a business network. Networks (formal or informal) can connect members to information, training and other resources, and potential business collaborators and mentors, thereby potentially improving the quality of their business operations (5-7). This, in turn, could hypothetically have positive impacts on production quantity and quality. In the case of agri-food businesses, this could translate into more and better food being available for population consumption (as well as greater employment and economic growth), although no specific evidence of such an effect exists.

The realisation of that potential, however, depend on women (and men) having equitable access to such networks and being able to benefit equitably from their services. Business networks, just like the firms and people of which they are comprised, are partly shaped by social norms, roles, and practices-including those related to gender. This means they have the potential to help increase women's empowerment and gender equity but also to reinforce existing gender gaps and biases within business. Better understanding how gender influences access to business networks and their resources, and how networks might affect male and female entrepreneurs differently, is central to steering their design and activities towards gender-sensitive or gender-transformative approaches (See Box 1 for explanations of these terms). 


\section{BOX 1. KEY GENDER-RELATED TERMINOLOGY}

Gender - A social and cultural construct distinguishing differences in the attributes of men and women, girls and boys. Gender refers to expectations about the roles, responsibilities, characteristics, aptitudes, and behaviours of women and men.

Gender equality - The equal rights, responsibilities, and opportunities of women and men, girls and boys, irrespective of being born male or female (and not implying equal outcomes).

Gender equity - The process of being fair to men and women, boys and girls, and importantly the equality of outcomes and results.

Gender blind - Not recognising that the roles and responsibilities of men/boys and women/girls vary and are partially dictated by their specific contexts and backgrounds (8).

Gender sensitive - Programmes and policies that are aware of and work with or around gender differences (8).

Gender transformative - Programming and policies that work to transform gender relations to achieve gender equity and other goals to which gender equity is instrumental (8).

This paper thus builds on a prior GAIN paper examining gender equity issues associated with food system businesses in LMICs (4) to review the literature on women and gender equity issues in business networks in LMICs. The insights emerging from the review are then used to offer recommendations for how to adapt business network-based programming to better promote gender equity. ' While many of the issues discussed here have resonance across diverse types of business networks, they are particularly relevant for business networks that aim to improve food security and nutrition, such as the Scaling Up Nutrition (SUN) Business Network (SBN, see Box 2). Of note, other non-gender factors related to an entrepreneur's identity (e.g., age, race, ethnicity, education) also shape their interactions with business networks; these are not covered here.

The next section summarises the methods used in the review, then the following sections outline main results, including the role of networks in general, women's interactions in business networks, and evidence on the potential for women-only networks to support female entrepreneurs. The penultimate section then offers recommendations for programmes that aim to support business networks in LMICs, with a particular focus on those related to the food system.

\section{METHODS}

This paper is based on a scoping review. Scoping reviews are useful for mapping existing areas of research, identifying gaps in the evidence, and summarising research results (9).

\footnotetext{
${ }^{1}$ While GAIN recognises that gender identifies are not necessarily binary, for the purpose of this paper, we choose to focus specifically on men and women.
} 
Unlike a systematic review, a scoping does not aim to be fully comprehensive and identify all studies on a given topic or provide a clear answer to a particular question or a definitive judgement of the effectiveness of different interventions (10). However, they allow for a broader scope of topic and range of study types and methodologies than traditional systematic reviews and are useful when a body of work is heterogeneous or spans multiple disciplines (11). The method is thus appropriate for the topic examined here, but it must be noted that the review did not aim to be comprehensive and uncover all work done related to women in business networks in LMICs but rather to identify the main themes emerging from that work (9).

Three methods were used to identify relevant work. First, literature was retrieved from Google Scholar using a series of keyword searches in November 2019 - January 2020. The first 100 results for each search (ranked by relevance) were reviewed by title for apparent relevance; relevant abstracts were then screened for inclusion. Second, searches of the websites of relevant international organisations (International Labour Organisation, SUN Business Network, UN Women, International Centre for Research on Women, and International Food Policy Research Institute) were carried out. Third, for each paper identified as relevant, we reviewed the paper's reference list and undertook Google Scholar searches for subsequent papers citing the paper in question. Where these added new or more up-todate information (or from a new geography), they were added.

To be included, publications needed to relate to business networks (formal or informal) and to discuss gender issues, men's or women's specific experiences, and/or differences between men and women. All types of studies were eligible for inclusion, with preference given to those sources that were based on empirical data. There were no date limitations. While there was a preference for studies from LMICs, most work was drawn from high-income countries due to limited high-quality information available from LMICs. Overall, the review draws on 44 publications, ten of which are specifically focused on LMICs; $91 \%$ were published in the past 20 years and $36 \%$ in the past 10 years.

\section{WOMEN IN BUSINESS AND BUSINESS NETWORKS: AN OVERVIEW}

\section{BARRIERS TO WOMEN IN BUSINESS IN LMICS}

General issues involving women and business are covered in depth in an earlier paper in this series (4). Here, we summarise these briefly before turning our focus to business networks, specifically.

Entrepreneurs, including those in the agriculture and food sectors, face considerable challenges starting and running businesses in LMICs. However, women often face additional barriers to business entry and growth (12), due both to discriminatory social and cultural norms and to unequitable institutional structures and policies (13). Women in LMICs tend to lack access to information, capital (including land and property to use as collateral), and technology $(14,15)$. They may have more limited financial and management knowledge as well as poorer basic literacy and numeracy $(13,14,16)$. Women also often face negative social attitudes, which can be a barrier to engaging in entrepreneurship (17-19). Home responsibilities and restricted mobility may further complicate their efforts to start and grow a 
business (4). Finally, given ingrained norms that place women in a lower social position than men in most LMICs, women may lack confidence and be hesitant to engage in a professional, business context $(14,20)$. Business networks can help to navigate some of these challenges.

\section{THE ROLE OF BUSINESS NETWORKS}

Networks can be either informal (e.g., family and friends) or formal (e.g., professional advisors, industry associations); many people are members of both, and the divisions between the two can be blurred (7). Formal networks can have various different membership structures. They can include those with specific roles within a specific field (e.g., Human Resources Managers of technology firms), those working in various different positions within different firms in the same field (e.g., those working in the agri-food industry), those with specific roles across fields (e.g., information technology managers), and those with a particular geographic or other affiliation (e.g., a local business association or an ethnic/religious business association). Within the food security and nutrition context, specifically, the Scaling Up Nutrition (SUN) Business Network is an example of a formal network that aims to help build business action to improve nutrition (see Box 2).

The main benefits of business networks for their members include sharing risk; accessing new markets, technologies, opportunities, and knowledge; gaining partners or suppliers; pooling complementary skills; accelerating the entry of products to market; and protecting property rights (5-7). Networks can also provide a form of collective action, allowing a group with shared interests to access resources or lobby for a common cause. Networks (formal and informal) can be a useful resource on which to draw when navigating challenge or adversity (21). Through networks, members can be connected to new organisations, such as the suppliers and retailers essential to starting a business. Network involvement is seen as positively associated with business growth and with raising capital (22), as well as with innovation $(23,24)$. Given the limited resources of small- and medium-sized enterprises to develop and manage wide and diverse networks of partners $(25,26)$, formal, externally organised networks can be particularly important to them.

Networks, however, also have drawbacks. When built off of existing relationships and attributes of social similarity, they can function as gatekeepers to preserve or even reinforce gender biases (such as stereotypes associated with a given gender) and other social barriers (27-29). Reliance on social capital and networks to advance business interests can thus reproduce the exclusion of those who are already socially marginalised and may lack access 
to such resources (27). When designing formal networks, it is thus essential to make them inclusive and open-while still remaining relevant to their members.

WOMEN IN BUSINESS NETWORKS

\section{BOX 2. THE SUN BUSINESS NETWORK}

In 2010, the Scaling Up Nutrition (SUN) Movement was launched to support national leadership and collective action to scale up efforts to end malnutrition worldwide. The SUN movement is active in over 61 member countries worldwide, supported by four global networks: the United Nations, Civil Society, Donor, and Business Networks. The SUN Business Network (SBN) is convened by GAIN and the United Nations' World Food Programme and further supported by an Advisory Group comprised of senior business leaders. SBN aims to reduce malnutrition in all its forms by mobilising business to invest and innovate in responsible, sustainable, and nutritionsupporting actions and operations. To do this SBN provides a neutral platform to broker partnerships and collaboration between business and other actors at national, regional, and global levels to support SUN Country plans.

As of December 2019, SBN was active in 14 countries, with an additional 27 country networks in development, as well as a global network. Most country-network members are local small- and medium-sized enterprises (SMEs), whereas those in the global network are mostly larger, multinational firms. At the national level, SBN holds meetings and events that bring together businesses, sometimes with government and other SUN networks, to mobilise business support for improving nutrition. It assesses the technical, financial, and other business support services that its business members need in order to act and invest in nutrition and facilitates links and partnerships with service providers to meet these needs. SBN runs pitch competitions to surface and support innovative business ideas related to nutrition and forges strategic partnerships with other business associations to further its goals. SBN encourages businesses to adopt responsible business practices, improve the nutritional content of their products, and make other commitments to improve nutrition. Finally, SBN advocates for an enabling environment that incentivises responsible business actions and investments.

At the global level, SBN acts as a focal point for engaging international businesses in nutrition actions, such as making commitments to improve the nutrition of their workforces, and fosters partnerships between investors and multinational companies to provide finance or technical assistance.

While women generally use networks in the same way men do (i.e., to develop skills, access work-related opportunities, or meet others who can help advance their careers), there can be some differences. Women tend to place a higher value on learning and skills development, gaining support, and sharing experiences $(7,22)$. Networks can be of particular value to women as a source of entrepreneurial know-how, which may not have been fostered in them by the education system and society to the same extent it was in men (due to social biases about who 'should' be an entrepreneur). Networks' role as a social outlet and in providing inspiration and support through difficult times can also be especially important for women 
$(21,22)$. However, many women (particularly senior managers) use networks primarily for business reasons, not social ones (7).

Women also have different access to networks than men. First, informal networks are often based around homophily (the tendency to associate with people who are similar, including with regard to gender) (30). Women tend to have ties to women in both social and work environments (22); in settings where women have less access to knowledge and other resources (e.g., financing, training, property, or equipment), this can be a disadvantage in starting or growing a business. However, women's tight social networks of other women can also provide advantages, such a strong mutual support systems (21).

Women's networks tend to be more geographically narrow, smaller, and more based on friends and family (thus comprised of stronger, closer contacts), whereas men's networks tend to be more formal and have a wider range of high-status and influential contacts as well as people they do not know well (28,31-34). These 'weak ties' offer diversity of information and resources and are thus more likely to bring new information useful to a business. Indeed, it has been shown that network heterogeneity can increase the likelihood of starting a business because it broadens the information and resources to which one has access (35). However, some argue that women's networks tend to be more heterogeneous than those of men. This is because women's business activities are more likely to be connected to other parts of life (31), because the limited number of women in business makes it impractical to form womenonly networks (36), or because women more actively seek out men as network ties (7). Indeed, the answer to whether women's and men's networks differ in structure varies widely by context (37).

Second, women can have difficulty breaking into predominantly male networks to gain access to information and resources $(7,38)$. Due to men's often higher social status and more senior roles within business, they may be advantaged in terms of the social and professional interactions that precede network ties (31). Men, as the dominant group within business, may want to maintain this dominance by excluding women (7). In addition, one's work history and existing social and professional ties help dictate how useful one may be perceived as a potential network member (31); women (who, due to gender biases, may have more limited work histories or fewer high-value ties) may be seen as less 'desirable' network members. Formal professional networks with open or transparent criteria-based membership may thus be particularly important to women to complement their narrower yet tighter informal networks (22). 


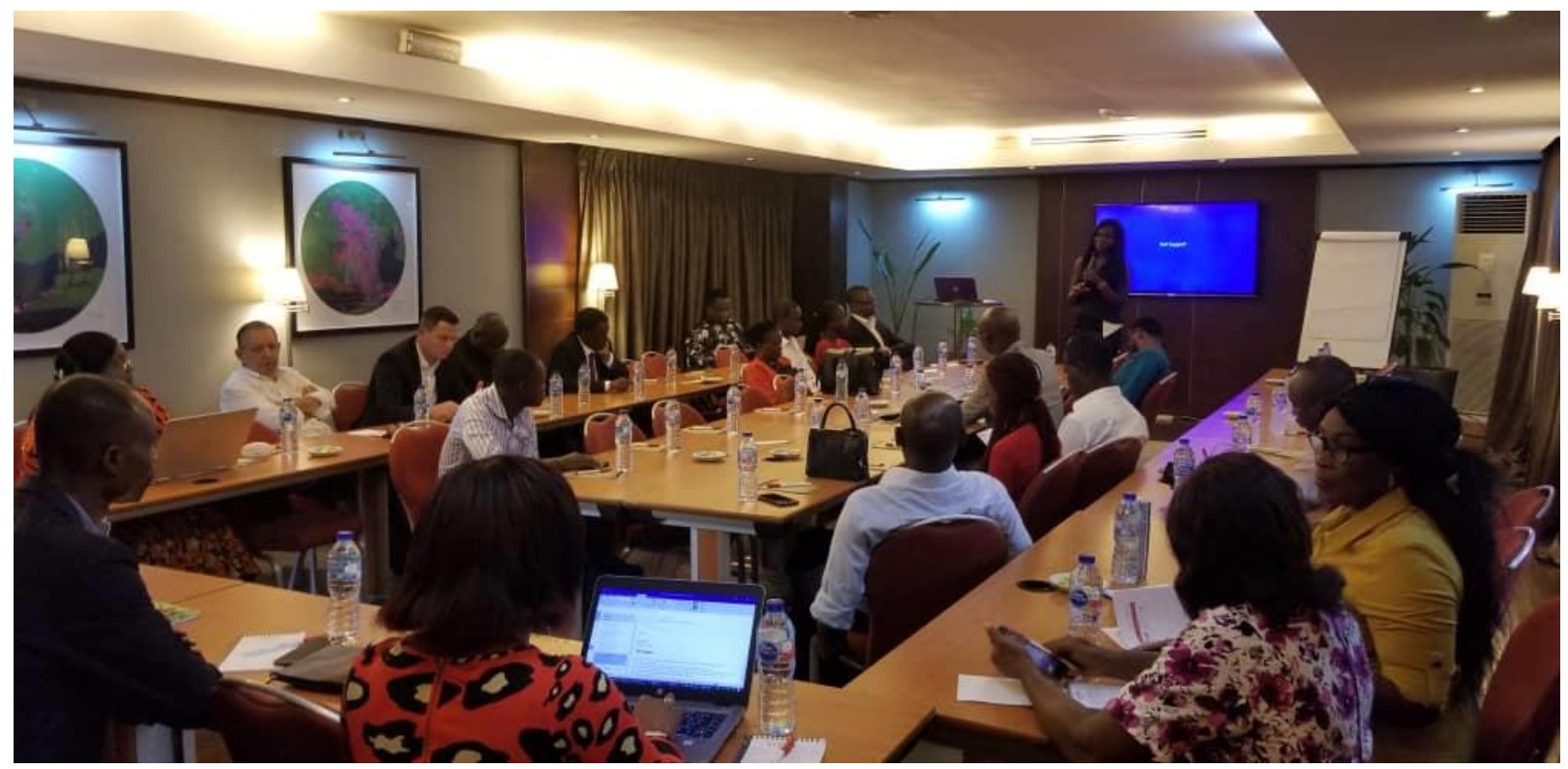

Figure 1. Attendees at an SBN-organised meeting in Nigeria, 2019

Third, accessing networking events and forums can be more difficult for women. Women are more likely to run home-based businesses, which can limit interactions with external resources (31). Women also often face larger burdens of unpaid domestic or social work (e.g., caring for children or elders); this may give them less time and schedule flexibility to engage in business network events and less formal professional socialising $(14,16,28,39)$. Limitations in mobility (either due to social norms, home obligations, or poorer access to transport) can also pose barriers. Locally based networks can thus be particularly important for female entrepreneurs $(39,40)$.

Even after joining a network, women may not benefit as much from membership as men if they are not seen as 'legitimate' members, have lower status than others (and thus are perceived as being less likely to reciprocate favours), and have not built up sufficient trust among other members $(32,40)$. The potential of business networks to empower women depends on women being able to effectively participate, to access resources and acquire skills, and to take on leadership roles. The empowering potential may be constrained by gender inequalities, including institutional constraints, social perceptions of women, and expectations of gender roles (41). Certain events organised by business networks, such as pitch competitions, may have specific gender-related barriers associated with attendance (see Box 3). 


\section{BOX 3. WOMEN AND BUSINESS PITCH COMPETITIONS}

While business pitch competitions (BPCs) are not a core component of business networks, some formal networks organise them for their members and others. Participation in BPCs can be important for obtaining financing or other support and can increase confidence and self-efficacy of the successful entrepreneur; some research has suggested that this benefit is larger for women than for men (42). However, BPCs are not without potential gender equity pitfalls.

A successful pitch relies on not only a fundamentally solid business plan but also on the entrepreneur's ability to communicate a vision and the evaluators' judgment of him or her as a 'successful entrepreneur' (43). These impressions may be influenced by gender and related expectations (44). In many countries, gender stereotypes position entrepreneurship as a 'masculine' activity $(44,45)$. Most entrepreneurial role models are men, a stereotype generally furthered by media coverage, and male-owned businesses tend to be more associated with investor-desired qualities such as rapid growth and innovation (44). Female entrepreneurs may thus be disadvantaged in BPCs because they do not conform to judges' expectations of a successful entrepreneur.

In addition, being assertive, competitive, dominant, and independent is typically associated with men whereas being nurturing, helpful, kind, and community-minded is associated with women (44). These norms are fostered in boys and girls, respectively, from a young age (46). The former set of characteristics also tends to be associated with successful business leaders-and with success in competitions. Such stereotypes can influence the way observers judge men and women in BPCs by (often unconsciously) comparing them to how they 'should' be. Experimental research in the United States has shown potential investors to prefer pitches presented by men over those presented by women, even when the content is identical (45). However, other studies suggest that it is not being a woman but rather displaying 'feminine' characteristics (e.g., warmth, emotiveness) that is punished in pitches-regardless of whether these traits are displayed by men or by women (47). Encouraging women to behave against gender stereotypes, such as by being very assertive, is not a clear solution, as they may be (consciously or unconsciously) judged negatively for violating gender norms (47). Indeed women who violate gender stereotypes in their work behaviour are often evaluated poorly by colleagues (48).

In some cultural settings, norms associated with women and public speaking and/or competition may discourage women from participation (in addition to barriers related to time availability and mobility). In addition, men tend to be both more competitive and more confident in their own abilities than women (46), making them more likely to enter competitions in general. The expectation that entrepreneurs are men may operate on women would-be pitchers, as well, making them less likely to participate, as they do not picture themselves as the expected winner. 


\section{WOMEN-ONLY NETWORKS}

There is some debate about the value of female-only versus mixed-gender networks in supporting women. Some have argued that female-only networks can play an important role, particularly in the early stages of a business or when social norms against women in business are strong and role models are needed. Women interviewed for a study in Pakistan, for example, felt that social norms about gender severely constrained their ability to engage in entrepreneurship and requested stronger business forums for women, as existing options had limited reach and poor-quality services (13). Businesswomen have reported several benefits to all-women's networks, including overcoming isolation, making contact with more experienced women in the same sector, and providing a sense of identity (49). Having access to women who are successful business owners and can act as role models and mentors can encourage other women to engage in entrepreneurship (50). Official women's enterprise associations at the national or sectoral level can also be a very powerful voice in representing women entrepreneurs in national advocacy processes (16).

However, gender-specific networks can cut women off from useful information held by men (32)_again, particularly in settings where men enjoy greater access to information and other resources. In settings with current or recent gender discrimination, men may be more valuable network ties than women, as they are more likely to occupy important positions within a firm (31). This can be especially true for more senior women, such as firm owners, who may seek higher-status ties through diverse networks $(7,32)$. Women entrepreneurs may also particularly value men as a source of practical business advice, likely due to perceived greater experience or legitimacy (51). Indeed, some researchers have found that, even if female entrepreneurs rely more heavily on other women, family, and friends in the early stages of a business, they later widen their networks to include both men and women and, eventually, shift toward more male-oriented networks (52). Some argue that women-only networks can be discriminatory or divisive-more likely to be a concern in settings where there is not already strict gendering of daily life_or can distract focus from targeting broader concerns, such as discriminatory policies (49).

\section{CAVEATS}

Before passing on to recommendations, several caveats to this review must be noted. First, the vast majority of research on women in business networks has focused on high-income countries, primarily in Europe or the United States, with very little evidence from diverse LMIC contexts. Norms around gender, work, and entrepreneurship are varied and fast changing, making it particularly difficult to make judgements based on research from an earlier time or a different geography. There is thus a need for additional research on the issue with a focus on LMICs and across varied settings. There is also a need for more research focusing on food system firms, specifically, to understand how the benefits and drawbacks of networks, and how women and men interact with them, may differ between the food sector and other sectors: due to a lack of specific evidence on networks within the food sector, this paper has focused on information related to business networks in general, drawing from that lessons for food system firms. There is also a need for work that better differentiates among 
different types of firms-in particular, micro-enterprises as opposed to small and mediumsized ones. Needs for and benefits from networks are likely to vary considerably by firm size and/or growth stage, but most research on the topic does not distinguish by these factors (in addition to gender).

Second, it is important to note that many barriers to engaging in entrepreneurship and business in LMICs are faced by men as well as women-even if some may be higher for women than for men. Women may also face unique opportunities as a result of their gender, and many do not see their gender as having any relationship to their business success. It is thus important to avoid over-emphasising the importance of gender-related factors, based on a thorough understanding of their importance within a given context and how female entrepreneurs themselves view the subject. Women entrepreneurs in LMICs are also not a homogenous group, and the opportunities and constraints they face vary widely. Finally, gender is only one component of identity, and women (and men) may be further advantaged or disadvantaged in terms of business networks based on their non-gender characteristics, such as rural residence or ethnicity (14).

\section{RECOMMENDATIONS}

Based on the results of this reviewed literature, a number of recommendations were made for how to better integrate gender equity into the work of business networks and alliances that work to improve nutrition and food systems-such as the SBN (Box 2) and GAIN's PostHarvest Loss Alliance for Nutrition (53).

\section{CONVENINGS, TRAININGS, EVENTS}

When planning events and meetings, it is important to assess female network members' needs and preferences for timing and location—considering family responsibilities, mobility limitations, and similar-and for format, such as a preference for small versus large group events, or for mentoring versus networking. Ideally, this assessment should cover nonmembers or non-attending women members, as well, to understand barriers to participation. This information can be used to adapt events to meet their needs. Conveners can also host women-specific networking and experience-sharing events for members. They could consider providing members with mentoring and training for broader skills (e.g., public communication), not just those specifically related to nutrition or business, as women may have less background and/or confidence than men in these areas. Finally, gender equity training can be included for all members, both men and women, within meetings and events.

\section{BUSINESS PITCH COMPETITIONS}

To make business pitch competitions, in particular, more gender equitable, pitch competition organisers can: (1) disseminate opportunities through women's organisations; (2) avoid single-gender judging panels; and (3) use women's participation within the business (e.g., women in leadership, a high percentage of women employees) or having a workplace gender equity policy as part of the competition's shortlisting or prioritisation criteria. 


\section{PARTNERSHIPS, ADVOCACY, AND SUPPORTING SERVICES}

Where networks work to lobby governments for a better enabling environment for business, they can promote policies that support gender equity (e.g., paid maternity and paternity leave, government-sponsored childcare, and workplace breastfeeding support legislation). Business networks can partner with women's business associations, women's chambers of commerce, and similar organisations for events and to expand membership. If they connect their members with service providers, mentors, or trainers, network conveners can work to ensure that the pool from which those resource people is drawn contains a diverse set of women.

\section{NETWORK OVERSIGHT}

To support this work, conveners should train their own staff on gender equity. They should also collect data on the gender of their members (women in leadership and employed), track event attendance by gender, and assess whether leadership roles in the network and speaking time at events are gender equitable. Finally, conveners should ensure that the network's media materials (e.g., training materials, brochures) include examples of both women and men filling diverse business roles.

\section{CONCLUSION}

This paper has attempted to bring a lens of gender equity to examine business networks for nutrition and food. It did so based on a summary of the literature on women in business networks in LMICs, which showed them to have numerous benefits for entrepreneurs, including women-but also potential pitfalls related to gender norms, roles, and stereotypes. These insights were then used to form recommendations for making the work of such networks more gender sensitive. Collectively, the recommendations offered should help organisations that convene networks ensure their work is more gender equitable and empowering of women.

Broadening the reach and impact of business networks for nutrition will not only help support gender equity -it can also help to achieve the broader goal of galvanising a range of diverse actors to take on the challenge of bringing an end to malnutrition in all its forms. 


\section{REFERENCES}

1. World Bank. Ease of Doing Business rankings [Internet]. Ease of Doing Business:

Rankings. 2020 [cited 2020 Sep 28]. Available from:

https://www.doingbusiness.org/en/rankings

2. Nordhagen S, Condés S, Garrett G. Blended finance: A promising approach to unleash private investments in nutritious food value chains in frontier markets [Internet]. Global Alliance for Improved Nutrition (GAIN); 2019 Nov [cited 2020 May 30]. Available from: https://www.gainhealth.org/sites/default/files/publications/documents/gain-discussionpaper-series-1-blended-finance-october-2019.pdf

3. Demmler K. The Role of Small and Medium-Sized Enterprises in Nutritious Food Supply Chains in Africa [Internet]. Global Alliance for Improved Nutrition (GAIN); 2020 Apr [cited 2020 May 25]. Available from:

https://www.gainhealth.org/sites/default/files/publications/documents/gain-workingpaper-series-2-the-role-of-small-and-medium-sized-enterprises-in-nutritious-foodsupply-chains-in-africa.pdf

4. Nordhagen S. Supporting Gender Equity through Food System Businesses in LowerIncome Countries. Geneva, Switzerland: Global Alliance for Improved Nutrition (GAIN); 2020. Report No.: GAIN Working Paper 11.

5. Pittaway L, Robertson M, Munir K, Denyer D, Neely A. Networking and innovation: a systematic review of the evidence: Networking and innovation: a systematic review of the evidence. Int J Manag Rev. 2004 Sep;5-6(3-4):137-68.

6. Farr-Wharton R, Brunetto Y. Women entrepreneurs, opportunity recognition and government-sponsored business networks: A social capital perspective. Women Manag Rev. 2007 May 15;22(3):187-207.

7. Durbin S. Creating Knowledge through Networks: a Gender Perspective. Gend Work Organ. 2011;18(1):90-112.

8. Gender Practitioners Collaborative. Minimum Standards for Mainstreaming Gender Equality. Washington, DC; 2018.

9. Arksey H, O'Malley L. Scoping studies: towards a methodological framework. Int J Soc Res Methodol. 2005 Feb 1;8(1):19-32.

10. Munn Z, Peters MDJ, Stern C, Tufanaru C, McArthur A, Aromataris E. Systematic review or scoping review? Guidance for authors when choosing between a systematic or scoping review approach. BMC Med Res Methodol. 2018 Dec;18(1):143.

11. Peters MDJ, Godfrey CM, Khalil H, Mclnerney P, Parker D, Soares CB. Guidance for conducting systematic scoping reviews: Int J Evid Based Healthc. 2015 Sep;13(3):141-6.

12. Klapper L, Parker S. Gender and the Business Environment for New Firm Creation. World Bank Res Obs. 2011 Aug 1;26(2):237-57.

13. Goheer N. Women entrepreneurs in Pakistan, how to improve their bargaining power. Geneva: International Labour Organization; 2003. 
14. De Groot TU. Women Entrepreneurship Development in Selected African Countries. Vienna: United Nations Industrial Development Organization; 2001. Report No.: Private Sector Development Working Paper 7.

15. Amine LS, Staub KM. Women entrepreneurs in sub-Saharan Africa: An institutional theory analysis from a social marketing point of view. Entrep Reg Dev. 2009 Mar $1 ; 21(2): 183-211$.

16. ILO. The Enabling Environment For Women In Growth Enterprises In Mozambique: Assessment Report. Geneva: Cilo Conulsting for the ILO; 2011. (WEDGE Southern Africa Program).

17. Woldie A, Adersua A. Female entrepreneurs in a transitional economy: Businesswomen in Nigeria. Int J Soc Econ. 2004 Jan;31(1/2):78-93.

18. De Vita L, Mari M, Poggesi S. Women entrepreneurs in and from developing countries: Evidences from the literature. Eur Manag J. 2014 Jun 1;32(3):451-60.

19. Richardson $P$, Howarth $R$, Finnegan $G$. The challenges of growing small businesses: Insights from women entrepreneurs in Africa. Geneva: ILO; 2004. (SEED Working Paper). Report No.: 47.

20. ANDE. Gender Equality in the SGB Sector. Washington, DC: Aspen Network of Development Entrepreneurs; 2019.

21. Ntseane P. Being a female entrepreneur in Botswana: Cultures, values, strategies for success. Gend Dev. 2004 Jul;12(2):37-43.

22. Dawson C, Fuller-Love N, Sinnott E, O'Gorman B. Entrepreneurs' Perceptions of Business Networks: Does Gender Matter? Int J Entrep Innov. 2011 Nov;12(4):271-81.

23. Beckeman M, Skjöldebrand C. Clusters/networks promote food innovations. J Food Eng. 2007 Apr;79(4):1418-25.

24. Zeng SX, Xie XM, Tam CM. Relationship between cooperation networks and innovation performance of SMEs. Technovation. 2010 Mar;30(3):181-94.

25. Hausman A. Innovativeness among small businesses: Theory and propositions for future research. Ind Mark Manag. 2005 Nov 1;34(8):773-82.

26. Colombo MG, Laursen K, Magnusson M, Rossi-Lamastra C. Introduction: Small Business and Networked Innovation: Organizational and Managerial Challenges. J Small Bus Manag. 2012 Apr;50(2):181-90.

27. Cleaver $F$. The inequality of social capital and the reproduction of chronic poverty. World Dev. 2005 Jun 1;33(6):893-906.

28. D'Exelle B, Holvoet N. Gender and Network Formation in Rural Nicaragua: A Village case study. Fem Econ. 2011 Apr 1;17(2):31-61.

29. Weiler S, Bernasek A. Dodging the glass ceiling? Networks and the new wave of women entrepreneurs. Soc Sci J. 2001 Mar 1;38(1):85-103.

30. McPherson M, Smith-Lovin L, Cook JM. Birds of a Feather: Homophily in Social Networks. Annu Rev Sociol. 2001;27(1):415-44. 
31. Loscocco K, Monnat SM, Moore G, Lauber KB. Enterprising Women: A Comparison of Women's and Men's Small Business Networks. Gend Soc. 2009 May 22;23(3):388-411.

32. McDonald S. What's in the "old boys" network? Accessing social capital in gendered and racialized networks. Soc Netw. 2011 Oct 1;33(4):317-30.

33. Watson J. Networking: Gender differences and the association with firm performance. Int Small Bus J. 2012 Aug 1;30(5):536-58.

34. Ridgeway CL, Smith-Lovin L. The Gender System and Interaction. Annu Rev Sociol. 1999;25(1):191-216.

35. Renzulli LA, Aldrich H, Moody J. Family Matters: Gender, Networks, and Entrepreneurial Outcomes. Soc Forces. 2000 Dec;79(2):523.

36. Ibarra H. Personal Networks of Women and Minorities in Management: A Conceptual Framework. Acad Manage Rev. 1993 Jan 1;18(1):56-87.

37. Doyle W, Young JD. Entrepreneurial Networks in the Micro-Business Sector: Examining Differences Across Gender and Business Stage. J Small Bus Entrep. 2001 Sep;16(1):4055.

38. Gamba M, Kleiner BH. The old boys' network today. Int J Sociol Soc Policy. 2001 Sep;21(8/9/10):101-7.

39. Cromie S, Birley S. Networking by female business owners in Northern Ireland. J Bus Ventur. 1992 May 1;7(3):237-51.

40. Hanson S, Blake M. Gender and Entrepreneurial Networks. Reg Stud. 2009 Feb;43(1):135-49.

41. Lecoutere E. The impact of agricultural co-operatives on women's empowerment: Evidence from Uganda. J Co-op Organ Manag. 2017 May 1;5(1):14-27.

42. Berger J, Myhrer A. The Effect of Business Plan Competitions on Entrepreneurial Intention and Behavior [Master's thesis]. [Trondheim]: Norwegian University of Science and Technology; 2012.

43. Clark C. The impact of entrepreneurs' oral 'pitch' presentation skills on business angels' initial screening investment decisions. Venture Cap. 2008 Jul;10(3):257-79.

44. Balachandra L, Briggs A, Brush, Candida, Eddleston K. Pitch like a Man: Gender Stereotypes and Entrepreneur Pitch Success. Front Entrep Res. 2013;33(8).

45. Brooks AW, Huang L, Kearney SW, Murray FE. Investors prefer entrepreneurial ventures pitched by attractive men. Proc Natl Acad Sci. 2014 Mar 25;111(12):4427-31.

46. Niederle M, Vesterlund L. Do Women Shy Away From Competition? Do Men Compete Too Much? Q J Econ. 2007 Aug 1;122(3):1067-101.

47. Balachandra L, Briggs T, Eddleston K, Brush C. Don't Pitch Like a Girl!: How Gender Stereotypes Influence Investor Decisions. Entrep Theory Pract. 2019 Jan;43(1):116-37.

48. Heilman ME, Wallen AS, Fuchs D, Tamkins MM. Penalties for Success: Reactions to Women Who Succeed at Male Gender-Typed Tasks. J Appl Psychol. 2004;89(3):416-27. 
49. Pini B, Brown K, Ryan C. Women-only networks as a strategy for change? A case study from local government. Women Manag Rev. 2004 Sep;19(6):286-92.

50. Bygrave W, Minniti M. The Social Dynamics of Entrepreneurship. Entrep Theory Pract. 2000 Apr 1;24(3):25-36.

51. Wan CK, Jaccard J, Ramey SL. The Relationship between Social Support and Life Satisfaction as a Function of Family Structure. J Marriage Fam. 1996;58(2):502-13.

52. Klyver K, Terjesen S. Entrepreneurial network composition: An analysis across venture development stage and gender. Women Manag Rev. 2007 Nov 13;22(8):682-8.

53. Yalch T, Lofthouse J, Nordhagen S. Creating alliances and fostering innovations to reduce postharvest food loss: Experiences from GAIN's Postharvest Loss Alliances for Nutrition [Internet]. Global Alliance for Improved Nutrition (GAIN); 2020 Sep [cited 2020 Oct 5]. Available from:

https://www.gainhealth.org/sites/default/files/publications/documents/gain-workingpaper-series-9-creating-alliances-and-fostering-innovations-to-reduce-post-harvest-lossof-nutritious-food.pdf 